\title{
LA-UR-12-23956
}

Approved for public release; distribution is unlimited.

Title:

Author(s):

Intended for:

\section{Suspect/Counterfeit Items Information Guide for} Subcontractors/Suppliers

Tessmar, Nancy D.

Salazar, Michael J.

Report

Disclaimer:

Los Alamos National Laboratory, an affirmative action/equal opportunity employer,is operated by the Los Alamos National

Security, LLC for the National NuclearSecurity Administration of the U.S. Department of Energy under contract DE-AC52-06NA25396. By approving this article, the publisher recognizes that the U.S. Government retains nonexclusive, royalty-free license to publish or reproduce the published form of this contribution, or to allow others to do so, for U.S. Government purposes.

Los Alamos National Laboratory requests that the publisher identify this article as work performed under the auspices of the

U.S. Departmentof Energy. Los Alamos National Laboratory strongly supports academic freedom and a researcher's right to publish; as an institution, however, the Laboratory does not endorse the viewpoint of a publication or guarantee its technical correctness. 
Title: Suspect/Counterfeit Items Information Guide for Subcontractors/Suppliers

Author(s): Nancy Tessmar; Michael Salazar

Referenced: Kenneth A. Brandt. (2007). LA-UR 073230 Los Alamos: Los Alamos National Laboratory.

Intended for: Suppliers, vendors, sellers, contractors, subcontractors, intending to provide items to Los Alamos National Laboratory or possibly other DOE sites. 


\section{Counterfeiting is not a victimless crime}

"It is a distressing but undeniable fact that there are unscrupulous vendors throughout the world that distribute defective products. There are also many instances where legitimate vendors unknowingly distribute items that do not conform to specifications because of deficiencies in design or manufacturing. These $\mathrm{SCl}$ and non-conforming items could break or fail in a way that could injure our workers or cause a safety system to fail."

The Deputy Secretary, Independent Oversight Special Study of the Department of Energy's Management of Suspect/Counterfeit Items, August 2003.

"The link between organized crime groups and counterfeit goods is well established. But Interpol is sounding the alarm that intellectual property crime is becoming the preferred method of funding for a number of terrorist groups. There are enough examples now of the funding of terrorist groups in this way for us to worry about the threat to public safety. We must take preventative measures now."

The links between intellectual property crimes and terrorist financing. Secretary General of Interpol, Ronald K. Noble, speaking before the U.S. House Committee on International Relations, July 16, 2003.

\section{Disclaimer}

This booklet provides information on individual components identified as suspect or suspect/counterfeit. Without additional information, the manufacturers or suppliers identified should not be considered as to have engaged in any wrongdoing. It is not necessarily a negative reflection on a supplier or manufacturer if their products are reported as suspect/counterfeit items $(\mathrm{S} / \mathrm{Cl})$. Reputable manufacturers and suppliers have a vital interest in preventing the manufacture and distribution of $S / C l$ associated with their names. The supplier or manufacturer may have been victimized and is pursuing $\mathrm{S} / \mathrm{Cl}$ associated with its products in an aggressive, prudent, and professional manner to get these items off the market. Therefore, each particular case must be examined on its own merit without making premature conclusions about the fault or culpability of the manufacturer or supplier whose name is associated with the $\mathrm{S} / \mathrm{Cl}$.

LA-UR-

Comments or questions: Contact Nancy Tessmar, (505) 665-3351; Email-ndt@lanl.gov 
Introduction

Counterfeiting- Simply, if a product can be manufactured, it can also be counterfeited.

Counterfeiting of industrial and commercial grade items is an international problem that places worker safety, program objectives, expensive equipment, and security at risk. In order to prevent the introduction of Suspect/Counterfeit Items $(\mathrm{S} / \mathrm{Cl})$, this information sheet is being made available as a guide to assist in the implementation of $\mathrm{S} / \mathrm{Cl}$ awareness and controls, in conjunction with subcontractor's/supplier's quality assurance programs.

When it comes to counterfeit goods, including industrial materials, items, and equipment, no market is immune. Some manufactures have been known to misrepresent their products and intentionally use inferior materials and processes to manufacture substandard items, whose properties can significantly depart from established standards and specifications. These substandard items termed by the Department of Energy (DOE) as $\mathrm{S} / \mathrm{Cl}$, pose immediate and potential threats to the safety of DOE and contractor workers, the public, and the environment. Failure of certain systems and processes caused by an $\mathrm{S} / \mathrm{Cl}$ could also have national security implications at Los Alamos National Laboratory (LANL).

Nuclear Safety Rules (federal Laws), DOE Orders, and other regulations set forth requirements for DOE contractors to implement effective controls to assure that items and services meet specified requirements. This includes techniques to implement and thereby minimizing the potential threat of entry of $\mathrm{S} / \mathrm{Cl}$ to LANL.

As a qualified supplier of goods or services to LANL, your company will be required to establish and maintain effective controls to prevent the introduction of $\mathrm{S} / \mathrm{Cl}$ into LANL. This will require that your company warrant that all items (including their subassemblies, components, and parts) sold to LANL are genuine ( i.e. not counterfeit), new, and unused, and conform to the requirements of the LANL purchase orders/contracts unless otherwise approved in writing to Los Alamos National Laboratory (LANL) contract administrator/ procurements specialist. See Attachment $1, \mathrm{~S} / \mathrm{Cl}$ Quality Clause, for further contractual information on $\mathrm{S} / \mathrm{Cl}$ requirements.

General Information

Suspect/Counterfeit Item

A suspect item is one in which there is an indication by visual inspection, testing or other information that it may not conform to established Government or industry-accepted specifications, or national consensus standards. A counterfeit item is a suspect item that is a copy or substitute, without legal right or authority to do so, or one whose material, performance, or characteristics are knowingly misrepresented by the vendor, supplier, distributor, or manufacturer. 
"Knockoff" parts are a growing concern in industry; they are inferior to design and reliability. Knockoffs are similar to counterfeited parts, but evade the patent and trademark laws by avoiding actual manufacturer brand names. They are reverse-engineered to look like the Original Equipment Manufacturer (OEM) products; often labeled/marked with OEM part numbers, and the packaging is almost identical to the OEM design. For the purpose of this guide, knockoffs will be categorized as $\mathrm{S} / \mathrm{Cl}$.

An item that does not conform to established requirements is not normally considered an $\mathrm{S} / \mathrm{Cl}$ if the nonconformity results from one or more of the following conditions:

- $\quad$ Defects resulting from inadequate design or production quality control;

- $\quad$ Damage resulting during shipment, handling, or storage;

- Improper installation;

- $\quad$ Deterioration during service;

- $\quad$ Degradation during removal;

- $\quad$ Failure resulting from aging or misapplication; or other controllable causes.

ITEMS PRONE TO BE COUNTERFEITED

Items prone to be counterfeited:

- $\quad$ Moderate or low-cost, high-demand or high turnover use items;

- $\quad$ Items easily copied by secondary market suppliers;

- Items that often bypass the vendor (seller or manufacturer) and are drop shipped to the requestor;

- $\quad$ Items that are not typically inspected;

- Items that are sold by un-authorized distributors.

Typical SIC items are:

- Used, rebuilt, or reconditioned items sold as new;

- Fraudulently marked or labeled as being manufactured by a recognized reputable company, or certified by a regulatory or certifying agency;

- Manufactured with misrepresented inferior materials or processes that create a potential for failure and exposure to hazards.

Industrial types of items, materials, parts, and components that have been counterfeited include, but not limited to:

- Hoists, as well as other hoisting, lifting, and rigging equipment;

- $\quad$ Electronic components, including capacitors, semiconductors and microcircuits;

- $\quad$ Valves, pipe, pipe fittings, and flanges;

- $\quad$ Fasteners, i.e., bolts, nuts, and washers.

Fastener: Metallic screw, nut, bolt, or stud having internal or external threads with a nominal diameter of $1 / 4$ inch $(6 \mathrm{~mm})$ or greater or a washer that is through-hardened or represented as meeting a consensus standard that calls for through-hardening, and that is grade identification marked or represented as meeting a consensus standard that requires grade identification marking.

- $\quad$ Electrical equipment and devices, including circuit breakers, connectors, and motors;

- Metal plates, bars, shapes, channel members, structural items, welding rods and electrodes. 
The listing of commercial grade items that have been counterfeited is extensive. Following is a partial listing:

- Batteries; camera, and cell-phone;

- Extension cords;

- Surge suppressors;

- Fire extinguishers;

- Automotive components, including oil filters and brake pads;

- Computer software.

\section{ENCLOSURES}

(1) $\mathrm{S} / \mathrm{Cl}$ Part Headmark List

(2) Suspect Item Indicator List

(3) SCl Examples

ATTACHMENT

(1) $\mathrm{S} / \mathrm{Cl}$ Quality Clause from Exhibit $\mathrm{H}$ 


\section{Enclosure 1}

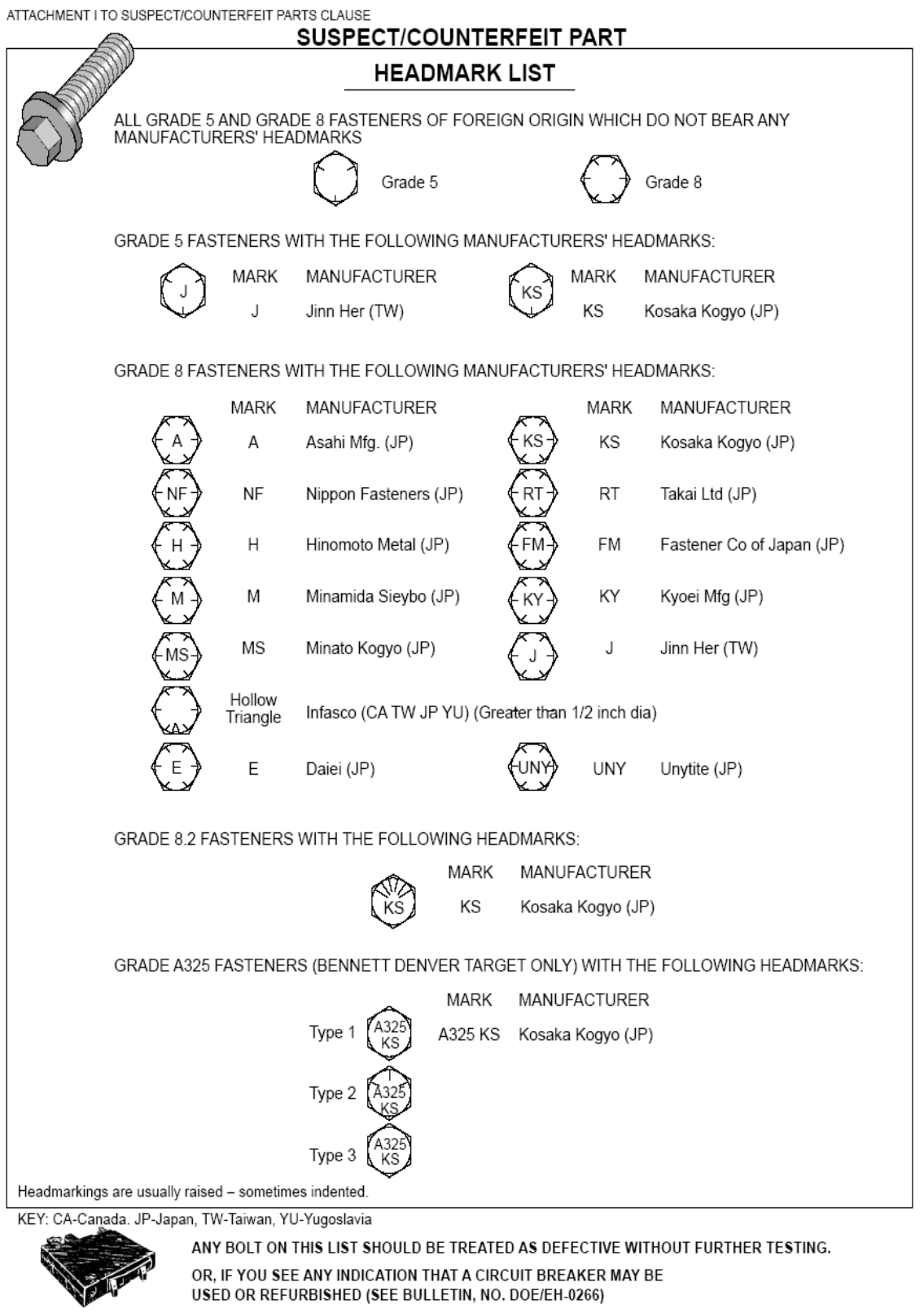

This list was prepared by the U.S. Customs Service after extensive testing of many samples of fasteners from around the United States. LANL considers any of these head marks as $\mathrm{S} / \mathrm{Cl}$. 
In many cases, a new counterfeit fastener has roughly the same physical strength as the graded fastener it mimics, but does not meet the chemical composition or heat treatment requirements specified in consensus standards. As a result, it will stretch, exhibit metal fatigue, or corrode under less harsh service than the genuine fastener.

Enclosure 2

Suspect Item Indicator List

The following is the suspect counterfeit indicator list that can be found in the DOE Suspect/Counterfeit Items On-line Resource Document.

SUSPECT ITEM INDICATOR LIST

Note: This information alone does not constitute an item or material as being $\mathrm{S} / \mathrm{Cl}$. Further research, such as a review of purchase orders, specifications, and certification/documentation is required before an item can be categorized as $\mathrm{S} / \mathrm{Cl}$.

\section{GENERAL INDICATORS}

- Visual Inspection

- Nameplates, labels, or tags that have been altered, photocopied, or painted over; are not secured well; are unusual in location and method of attaching; have incomplete data; or are missing, preprinted labels that show typed entries.

- Item has wear marks or scratches on external surfaces.

- Obvious attempts at repair or beautification have been made, such as excess painting or wire brushing; evidence of hand-painting (touch-up), painted stainless steel; non-ferrous metals (e.g., copper, brass, bronze) are clean and bright indicating recent polishing.

- Handmade parts are evident; gaskets are rough-cut; shims and thin metal part edges show evidence of cutting or dressing by hand tools (filing, hacksaw marks, tin snips, or nippers).

- Assembled items fit poorly.

- Metallic items are pitted or corroded.

- Heat discoloration marks.

- Casting markings have been ground off and the item has been re-stamped with other markings.

- Configuration is not consistent with other items from the same supplier or varies from that indicated in supplier literature or drawings.

- Inconsistency between vendor (seller or manufacturer) name on the item and on the shipping container.

- Nameplates attached with inconsistent fasteners, such as screws instead of rivets, or a combination of rivets and screws.

- Nameplates attached in a different location than normal.

- Warning labels with grammatical errors and conflicts with information found elsewhere on the packaging.

- Nameplates missing manufacturer's standard markings, stamps, or logos, or with irregular stamping or inconsistent type (font).

- Inconsistent appearances of items in the same shipment. 
- Shipping boxes/totes containing mixed batch numbers, expiration dates, and uniform product codes (UPC).

- The item or component matches the description of one that is listed on a suspect item list (e.g., DOE Suspect/Counterfeit Part Headmark List -Enclosure 1).

- Unusual packaging and boxing of items. Packaging is inconsistent with the manufacturer's normal packaging or documentation requirements.

- Questionable or meaningless numbers on the item(s) or packaging.

- Signs of weld repairs.

- Country of origin is China, Taiwan, India, Korea, Philippines, Thailand or Mexico.

- Underwriters Laboratories (UL) marks missing one or more of the four elements (UL trademark, the word LISTED in capital letters, product identity, and a control number) ; a UL mark on the package but not on the product.

\section{Procurement}

- Quoted price for the item is unusually discounted or low.

- Unusual disclaimers or denials of responsibility for the accuracy of the test results, etc.

- The supplier is not a manufacturer's authorized distributor.

- Dimensions of the item are inconsistent with the specification requested on the purchase order even though that is what is provided by the manufacturer at the time of the shipment.

\section{Documentation}

Documentation may be suspect or fraudulent when:

- The use of correction fluid or correction tape is evident.

- Type style, size, or pitch change is evident.

- Documentation is not signed or initialed when required.

- It is excessively faded or unclear (indicating multiple, sequential copying), or data is missing.

- The name of the document approver, or title, cannot be determined; the document has missing or illegible signature, initials; the approvers name and signature does not match.

- Technical data is inconsistent with code or standard requirements.

- Certification or test results are identical between items when normal variations should be expected.

- Document is not traceable to the items procured.

- Corrections are not properly lined-out, initialed and dated.

- Documentation is not delivered as required on the purchase order, or is in an unusual format.

- Lines on forms are bent, broken, or interrupted indicating data has been deleted or exchanged by "cut and paste."

- Handwritten entries are on the same document where there is typed or preprinted data.

- Text on page ends abruptly and the number of pages conflicts with the transmittal.

- Data on a single line is located at different heights. 
- All fields on a document must be filled in with data.

Note: For a more extensive listing of indicators please refer to the DOE HSS Suspect/Counterfeit Items On-line Resource Document

Enclosure 3

S/Cl Examples

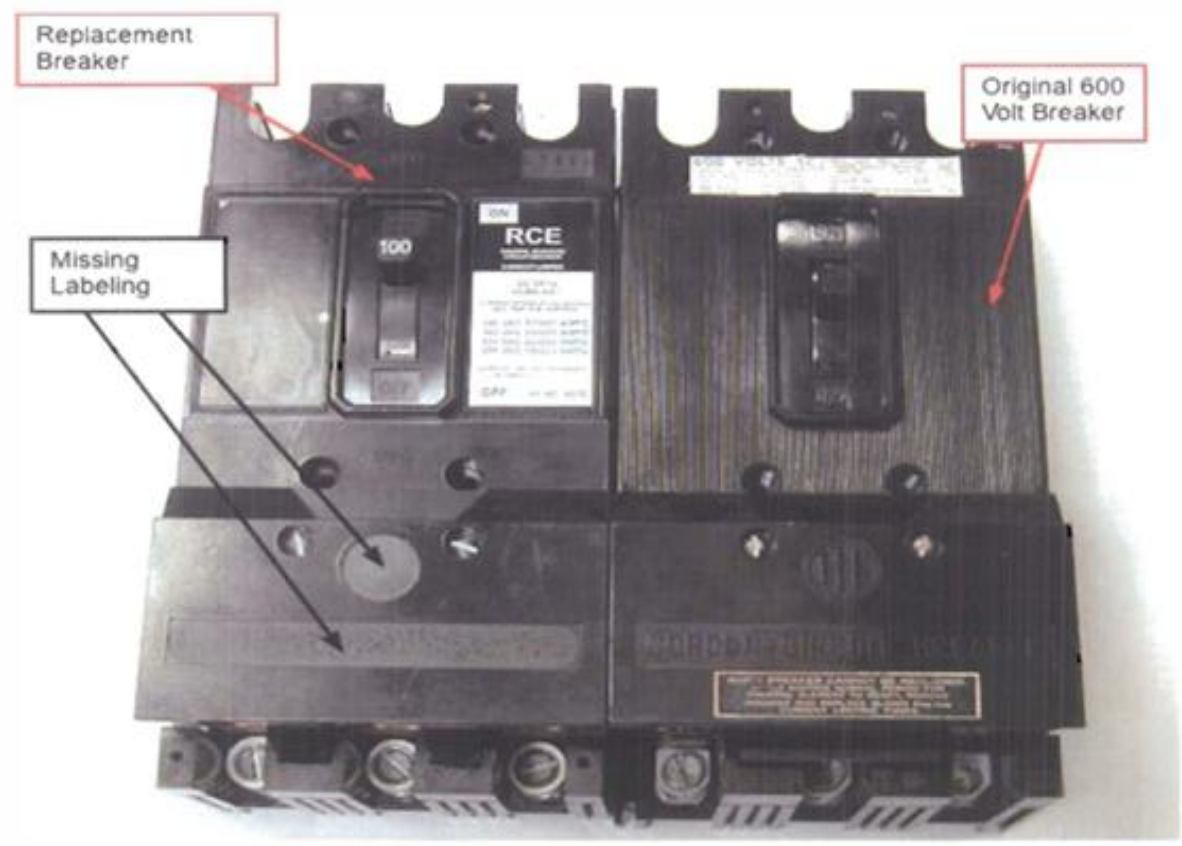

Circuit Breakers.

Suspect indicators - missing information

Left - Used 600 volt, 100 amp breaker sold as "new".

Right - Original breaker 


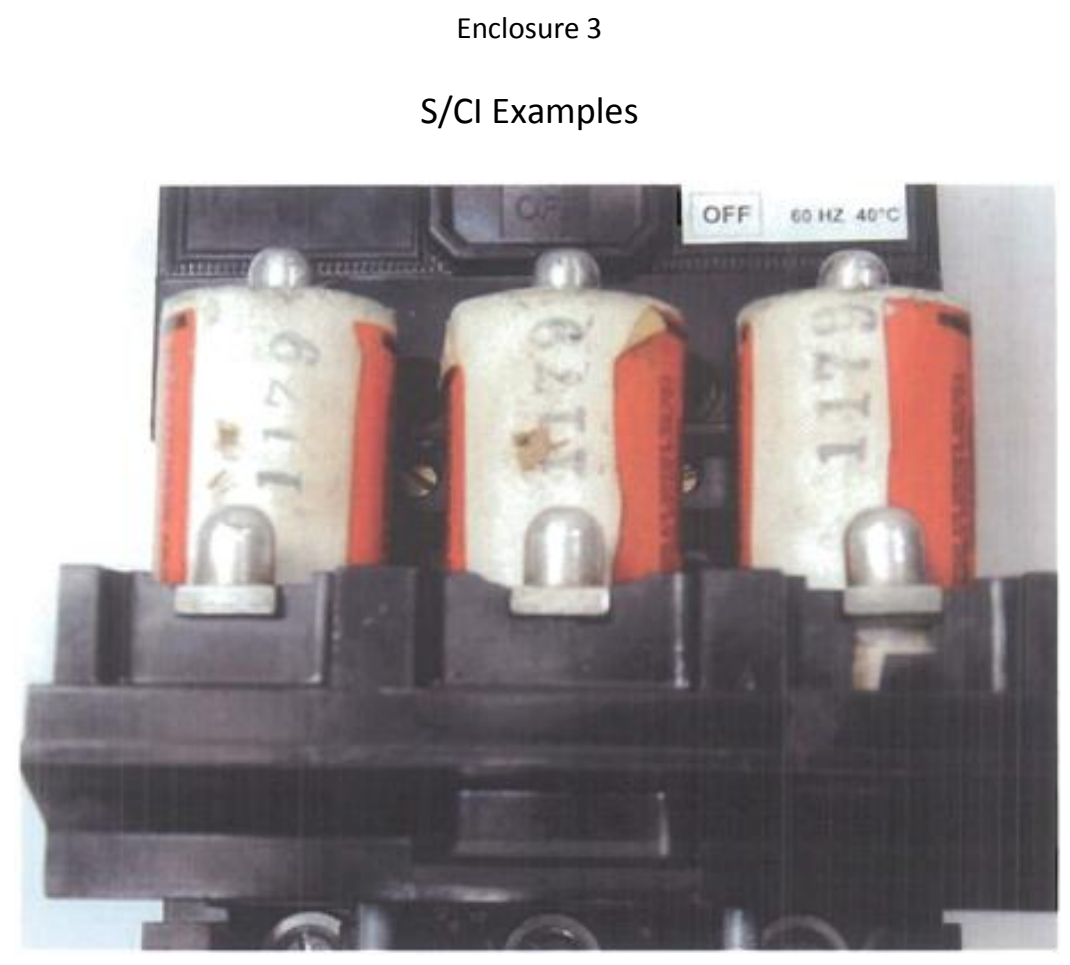

Fuses.

$\mathrm{S} / \mathrm{Cl}$-Used internal components within 600 volt, $100 \mathrm{amp}$ breaker sold as new and unused.

Hook, lifting.

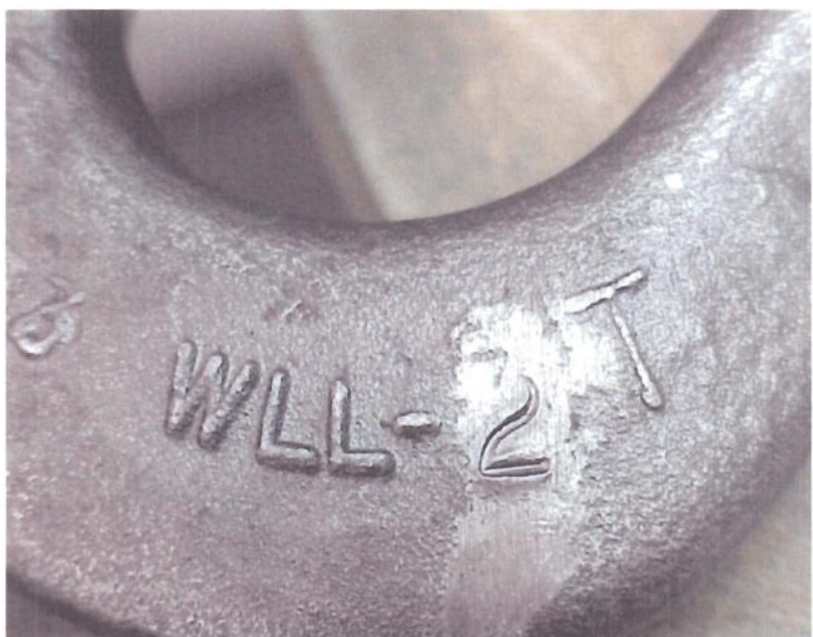

$\mathrm{S} / \mathrm{Cl}$-Altered working load limit (WLL) marking. 


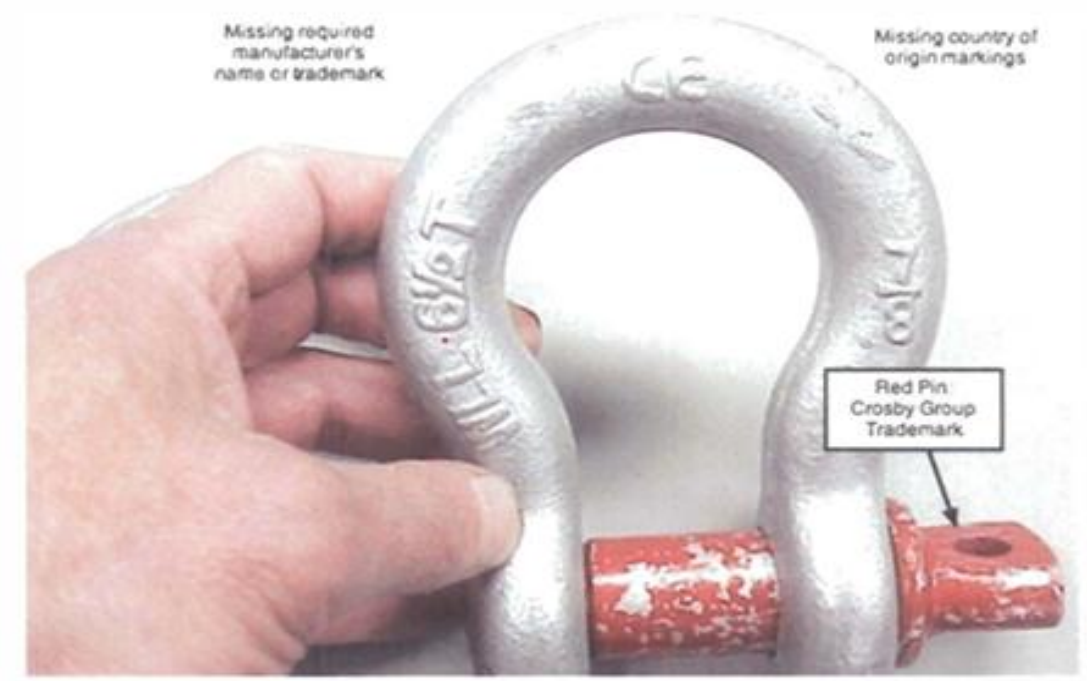

Shackle.

$\mathrm{S} / \mathrm{CI}$ - Trademark violation. 6-1/2 Ton rated screw pin shackle, minus any manufacturer's name or logo, and country of origin. The red colored screw pin is a Crosby Group trademark.

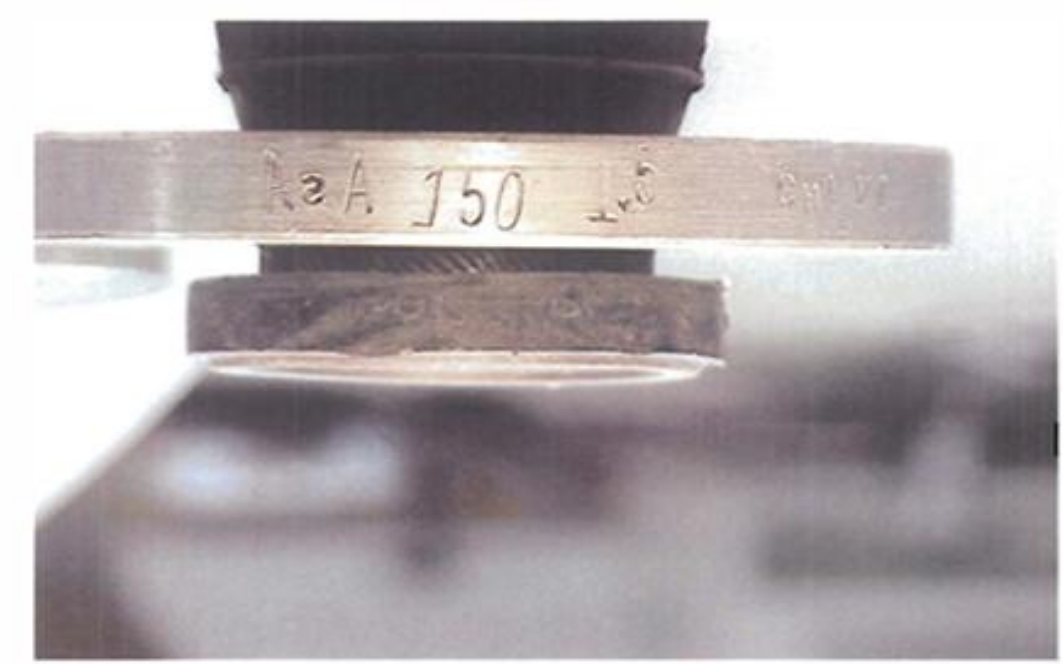

Flange.

Suspect indicator - Hand stamping 


\section{S/CI Examples}

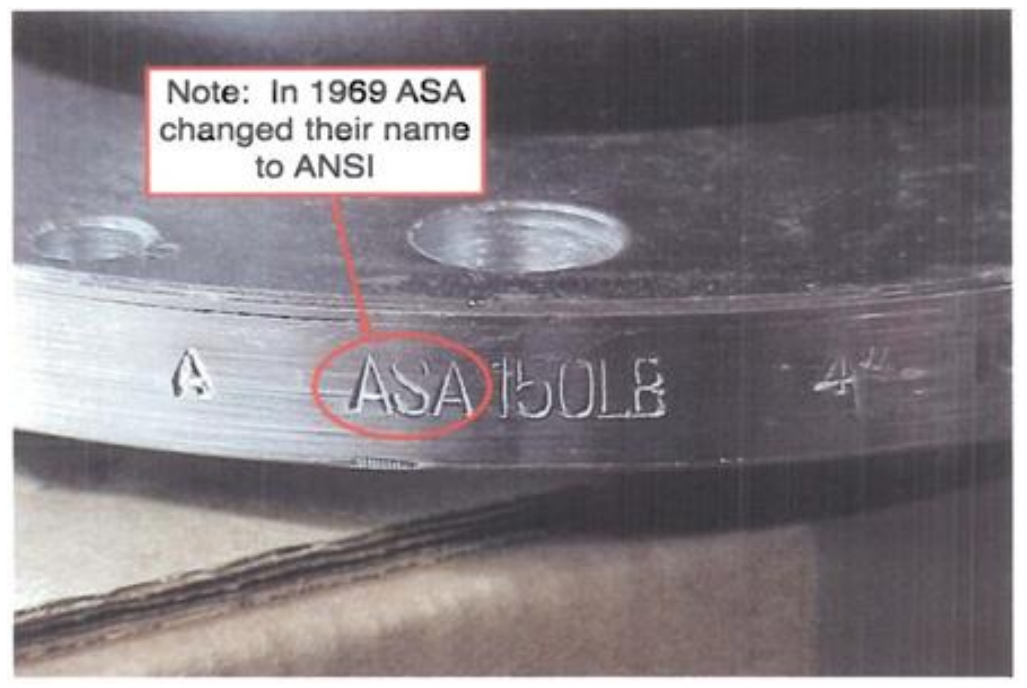

\section{Flange.}

Suspect Indicator- Meaningless information; ASA is a reference to an obsolete consensus standards organization.

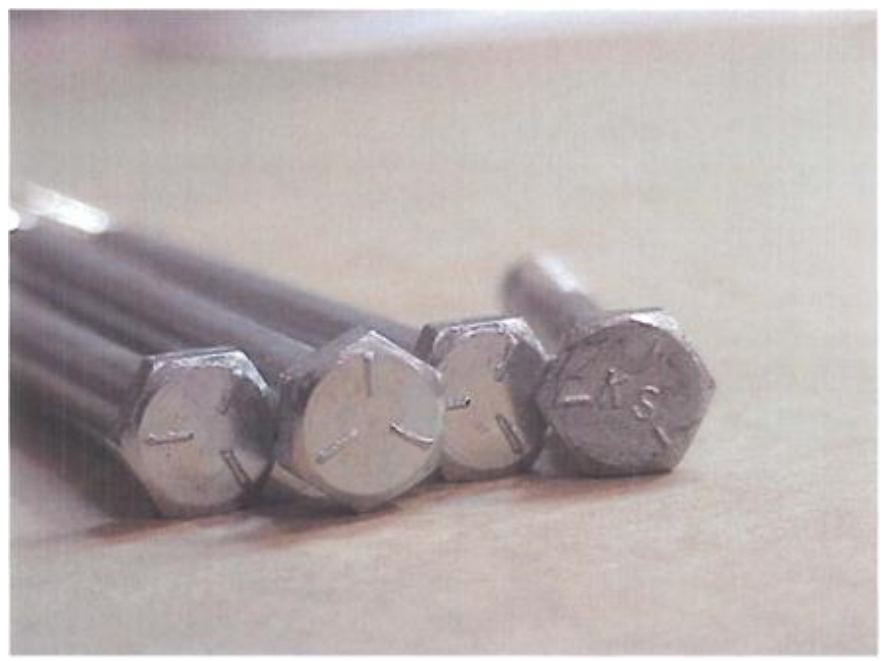

Bolts.

S/CI- SAE grade 5 (ASTM A 449) bolts. From the left- the first three are missing the required manufacture's symbol, and the fourth bolt has the "KS", Kosaka Kogyo insignia. All four are on the DOE SC/I Part Headmark List (Enclosure 1) 
Enclosure 3

\section{$\mathrm{S} / \mathrm{Cl}$ Examples}

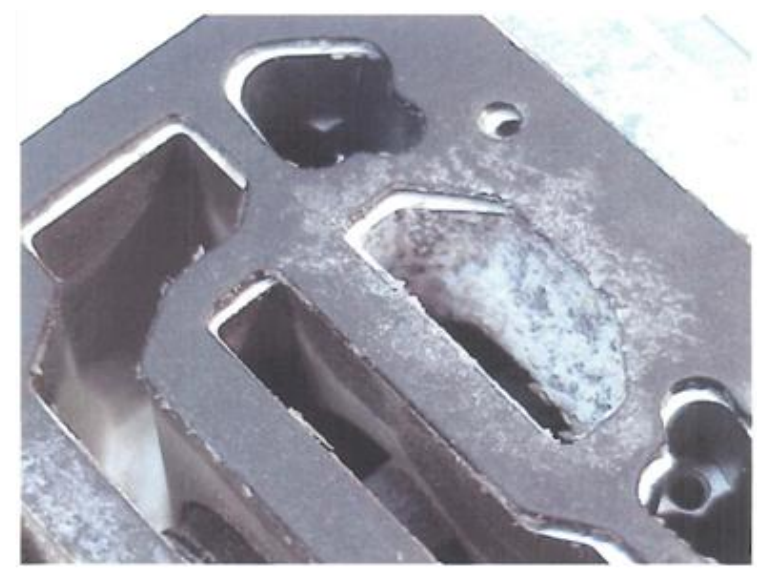

Valve, internal,

$\mathrm{S} / \mathrm{Cl}$ - Internal corrosion of an air-dryer valve sold as "new."

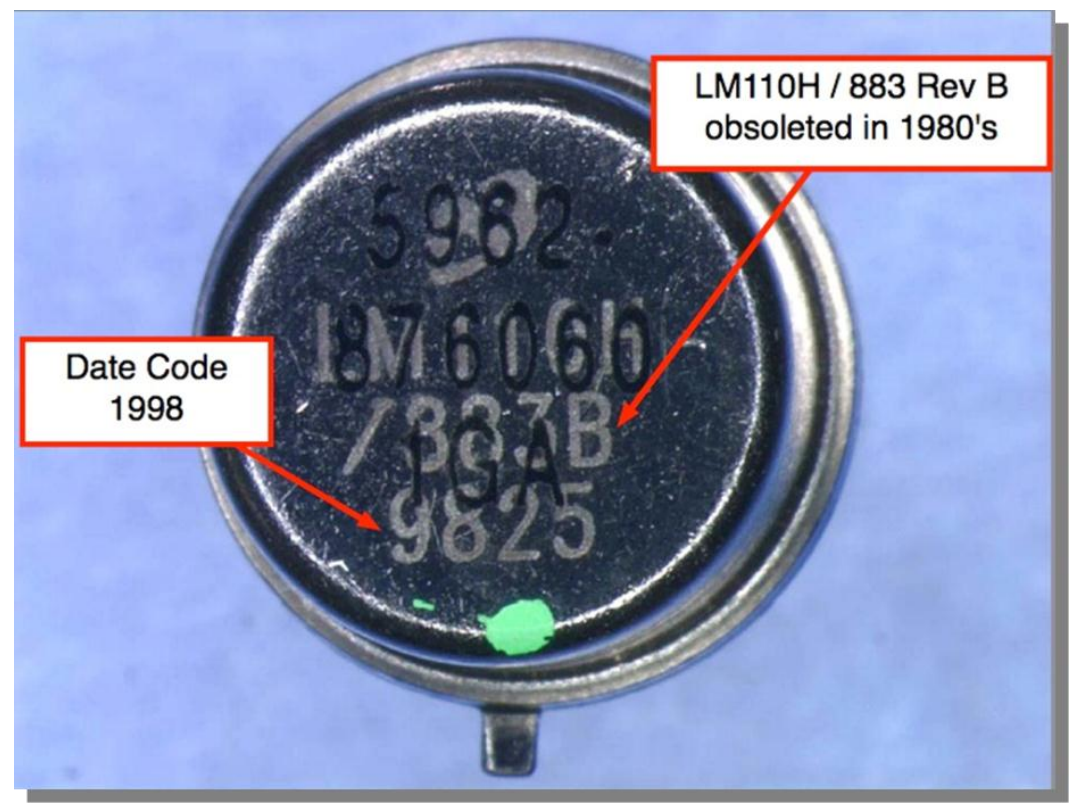

MIL-SPEC Semiconductors

$\mathrm{S} / \mathrm{Cl}$ - The two stampings on this particular item contradict themselves. The date for this semiconductor is 1998 but the model number stamped was obsolete in the 1980's. 
Enclosure 3

$\mathrm{S} / \mathrm{Cl}$ Examples

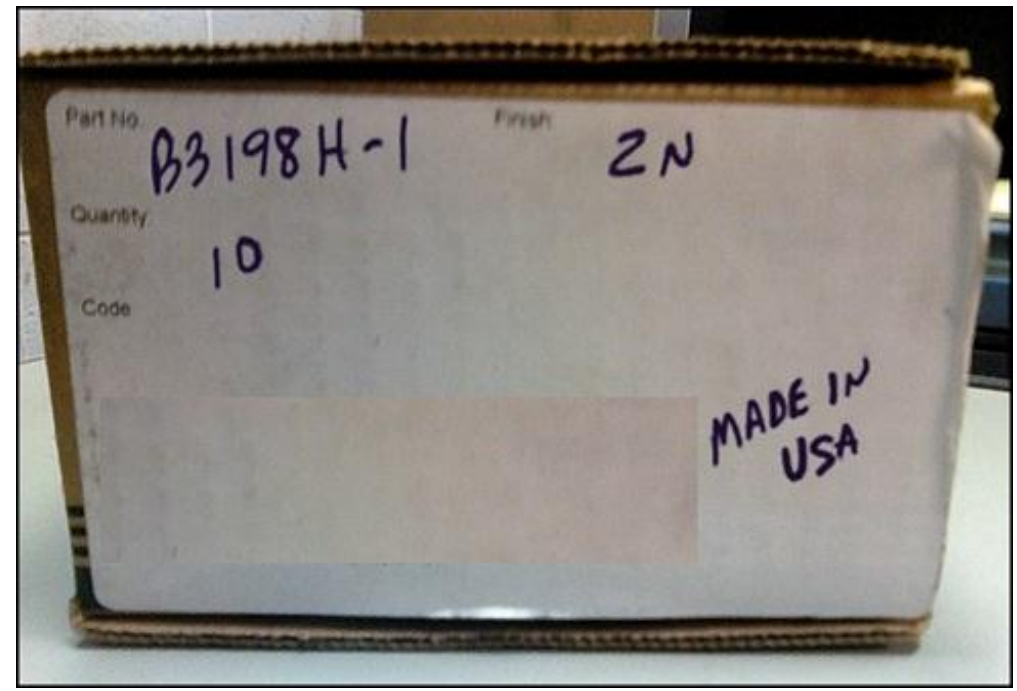

Packaging for electrical conduit clamps

Suspect indicator- Any kind of label that is hand written should be considered suspect/counterfeit because there is no validity attached to this package.

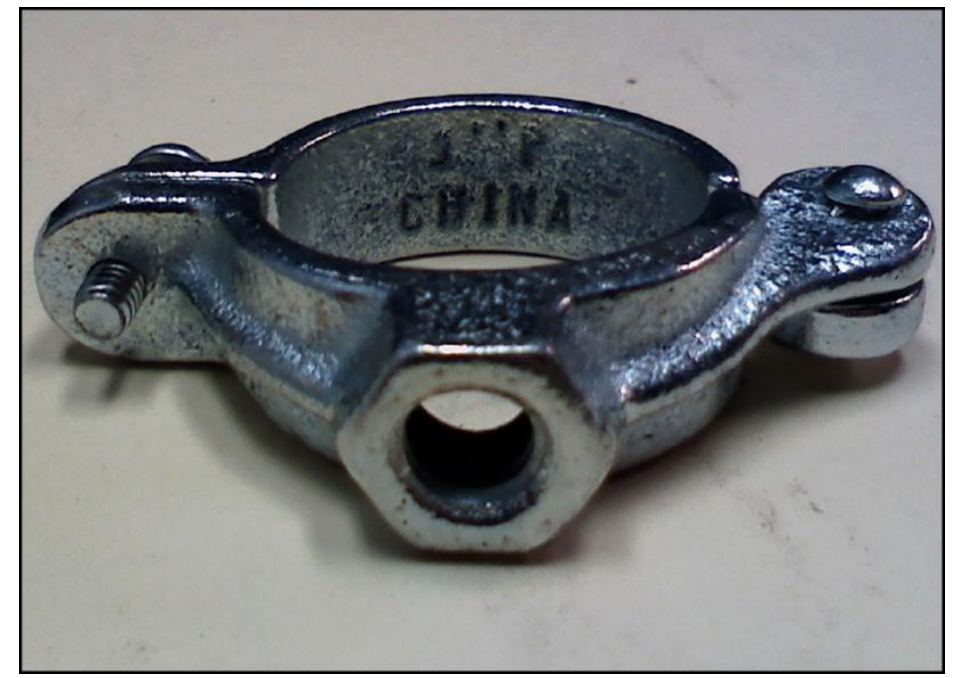

Electrical conduit clamps

Suspect indicator- The package which contained these items was marked, "MADE IN USA" and was handwritten on the label which makes these clamps a suspect item. These clamps are marked "CHINA" which exemplifies the use of misrepresentation resulting in a counterfeit item. 


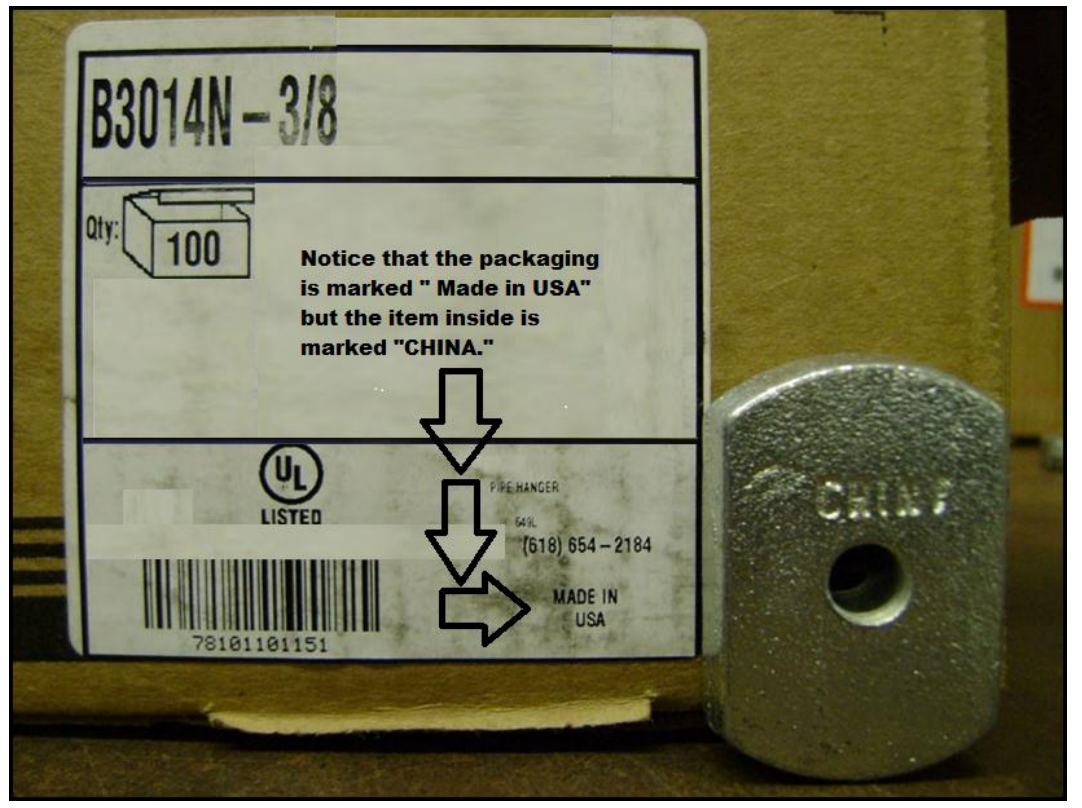

Spacer.

In comparison to the previous example, the label is printed and looks to be acceptable but when the package is opened, inside are these spacers that are marked "CHINA."

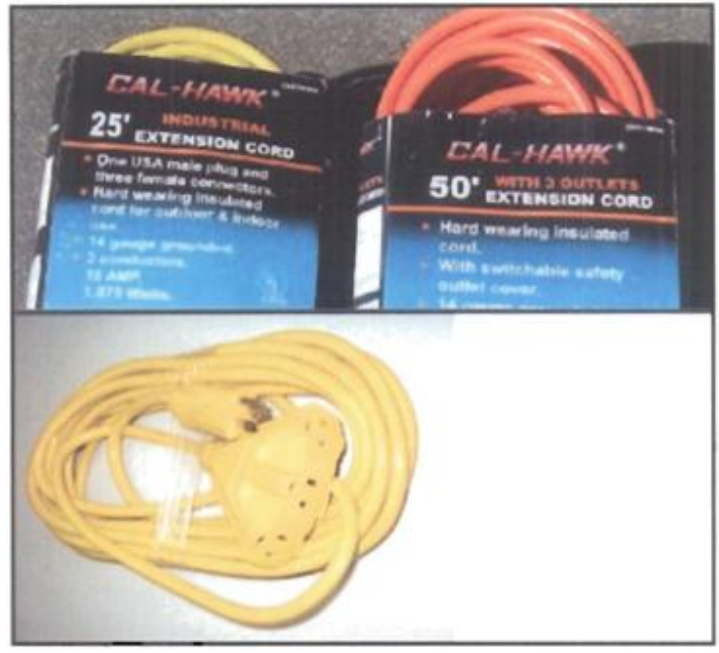

Extension cords.

$\mathrm{S} / \mathrm{Cl}$ - Underwriters Laboratories (UL) Inc. issued an alert regarding 25 and $50 \mathrm{FT}$. cords. The cords are marked as UL listed and having 14 gauge wires. These have not been approved by UL and the wire size is actually significantly undersized, leading to potential hazards. 


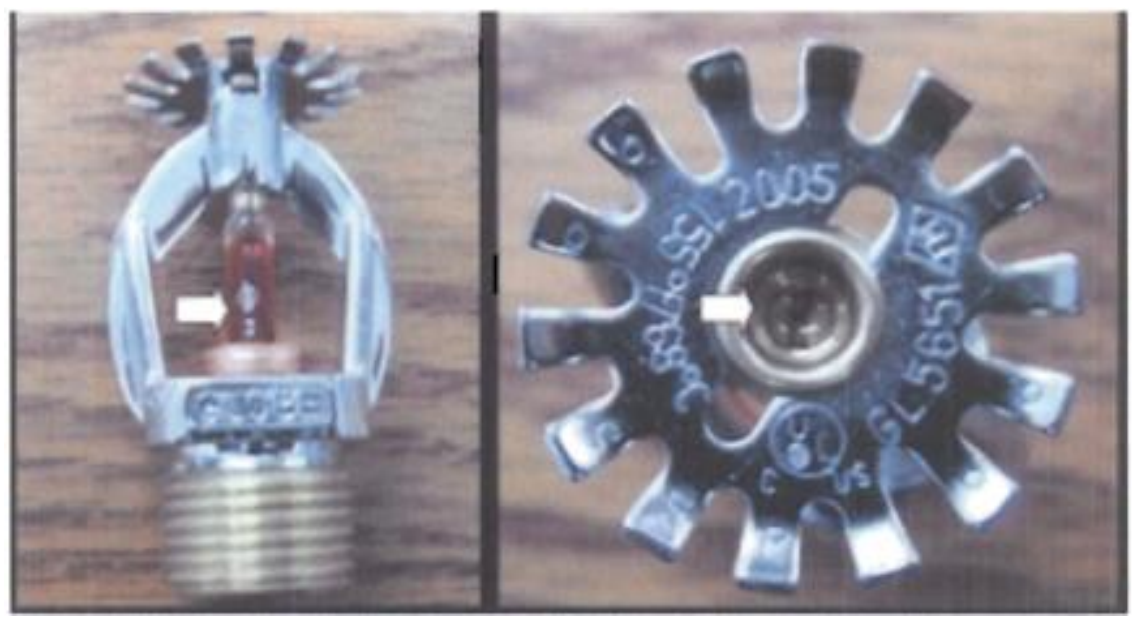

Sprinkler heads, fire protection.

S/Cl- UL issued two alerts in 2006 regarding Chinese manufactured sprinkler heads having counterfeit UL marks.

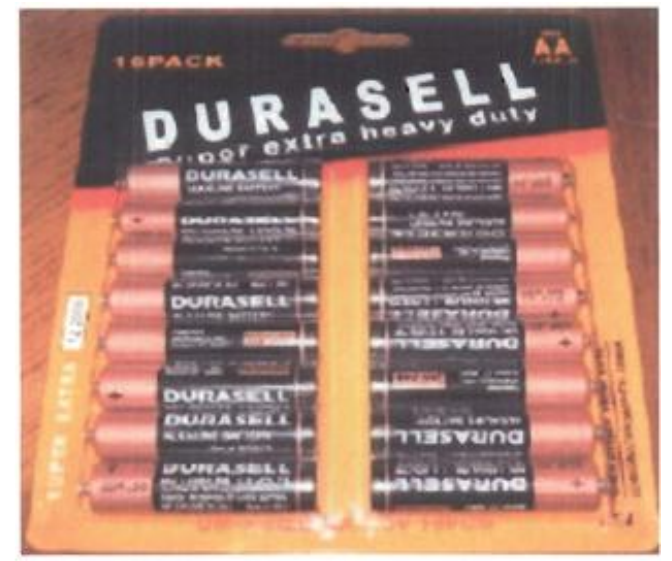

Batteries.

S/Cl- "Copper Top" trademark violation 1 and confusingly similar name ${ }^{2}$ of the manufacturer "Duracell." Counterfeit batteries present a higher risk of malfunction; constructed without adequate vent holes (safety feature), and often contain mercury, a heavy metal that damages the central nervous system when ingested and can harm the environment when the batteries are discarded.

${ }^{1}$ Counterfeit indicator

${ }^{2}$ Suspect indicator 


\section{CONTACT}

Nancy Tessmar

Suspect/Counterfeit Item Coordinator

Los Alamos National Laboratory

Los Alamos, New Mexico 87545

P.O. Box 1663, MS C339

505-665-3351

Email-ndt@lanl.gov

TRAINING

Los Alamos National Laboratory

LANL Course \# 39907

Suspect/ Counterfeit Items Overview

Registration via e-mail - $\underline{\text { scic@lanl.gov }}$

\section{INTERNET RESOURCES}

Underwriters Laboratories Inc.

http://www.ul.com/newsroom/notices.html

http://www.ul.com/ace/fake.html

The United States Patent and Trademark Office

http://www.uspto.gov/

Fleet Owner- Counterfeit Parts Buyer Beware

http://fleetowner.com/mag/fleet counterfeit parts buyer/index.html 
Public Laws

PUBLIC LAWS

Stop Counterfeiting in Manufacturing Goods Act. Public Law 109-181. March 16, 2006

Fastener Quality Act. Public Law 101-592.

Attachment 1

S/CI Quality Clause

Suspect/Counterfeit Items Quality Clause included in many LANL procurements (LANL Exhibit H, Quality Assurance Supplement, 06/11)

\section{QC-27 SUSPECT/COUNTERFEIT ITEMS (Jun 2011)}

(a) A suspect item is one in which there is an indication by visual inspection, testing, or other information that it may not conform to established Government or industry-accepted specifications or national consensus standards. A counterfeit item is a suspect item that is a copy or substitute, without legal right or authority to do so, or one whose material, performance, or characteristics are knowingly misrepresented by the vendor, supplier, distributor, or manufacturer.

(b) SUBCONTRACTOR warrants that all items, including their subassemblies, components, and parts, tendered to CONTRACTOR shall be genuine (i.e., not counterfeit), new and unused, and conform to the requirements of this subcontract, without substitution unless otherwise provided for within this subcontract or approved in writing by CONTRACTOR prior to delivery.

(c) SUBCONTRACTOR further warrants that all components, parts, materials, and supplies incorporated into CONTRACTOR'S facilities or equipment by SUBCONTRACTOR, during performance of 
work at LANL, shall be genuine, new and unused, and original-equipment-manufacturer items, without substitution unless otherwise provided for within this subcontract or approved by CONTRACTOR in writing as suitable for the intended purpose prior to use.

(d) As part of the foregoing warranties, SUBCONTRACTOR also certifies that all labels and/or trademarks or logos affixed, or designed to be affixed; to items supplied or delivered to CONTRACTOR, and to certifications, affirmations, information, or documentation related to the authenticity and quality of items supplied or delivered to CONTRACTOR under this subcontract, are genuine.

(e) Falsification of information or documentation may constitute criminal conduct; accordingly, SUBCONTRACTOR grants CONTRACTOR the right to temporarily segregate items, and related paperwork, that are suspected to be $\mathrm{S} / \mathrm{Cl}$, pending a determination by National Nuclear Security Administration (NNSA) or Department of Energy (DOE) officials whether the segregated items should be impounded as evidence.

(1) In the event NNSA/DOE directs CONTRACTOR to impound the segregated items, no liability shall be asserted or enforceable against CONTRACTOR, NNSA, or DOE because of the impoundment, all such liability being expressly waived by SUBCONTRACTOR or any person claiming any right or interest under this subcontract in the impounded items.

(2) CONTRACTOR shall incur no liability for failure to return impounded items to SUBCONTRACTOR and does not assume any liability for loss or damage to the items impounded or temporarily segregated pursuant to this clause regardless of the circumstances under which said loss or damage may have occurred, and whether the impounded or temporarily segregated items are in CONTRACTOR'S possession or under its control.

(f) Nothing in this clause shall limit CONTRACTOR'S right to reject $\mathrm{S} / \mathrm{Cl}$, and related paperwork, as nonconforming, to deny payment for such items, to return such items to SUBCONTRACTOR once NNSA/DOE has released the items, or to assert other remedies provided under this subcontract or by law. 